\section{Chronic myeloid leukemia mimicking primary myelofibrosis: A case report}

\author{
Anju S*, Jayalakshmy PL and Sankar Sundaram
}

Junior Resident, Government Medical College, Kottayam, Kerala, India
Received: 02 November, 2020

Accepted: 01 February, 2021

Published: 02 February, 2021

*Corresponding author: Anju S, Junior Resident, Government Medical College, Kottayam, Kerala, India, Tel: 91 9496057350; E-mail: anjuspkv.791@gmail.com

Keywords: Chronic myeloid leukemia; Primary myelofibrosis; Blast crisis; Myeloproliferative neoplasms

https://www.peertechz.com

Check for updates

\title{
Abstract
}

Bone marrow fibrosis leading to dry tap aspiration and often associated with blast crisis has previously been reported in both Chronic myeloid leukemia and Primary myelofibrosis. The similarities between these two conditions in terms of clinical presentation and morphology can really create a diagnostic dilemma. Here we present a case of Chronic myeloid leukemia in fibrosis and blast crisis in a 32 year old lady which closely resembled Primary myelofibrosis in transformation. All myeloproliferative neoplasms can undergo blast transformation. In this case, the detection of Philadelphia chromosome helped to distinguish Chronic myeloid leukemia from other myeloproliferative neoplasms.

\section{Introduction}

Myeloproliferative Neoplasm (MPN) results from unchecked proliferation of the cellular elements in the bone marrow characterized by panmyelosis and accompanied by erythrocytosis, granulocytosis, and/or thrombocytosis in the peripheral blood. Although trilineage cell involvement is characteristic of MPN, a single cell line is more prominently affected. The primary defect in MPN is in the pleuripotent hematopoietic stem cell. The Philadelphia chromosome containing BCR-ABL1 fusion gene is found in all hematopoietic cells in patients with Chronic Myeloid Leukemia (CML), while Janus Kinase (JAK2) gene was found to be mutated in almost all cases of Polycythemia vera and some cases of Essential thrombocythemia and Primary Myelofibrosis (PMF). CML is the most common MPN, accounting for $15-20 \%$ of all leukemia cases. It can occur at any age, but the incidence increases dramatically among those who are 55 years of age and older. CML can occur in young adults more so than other MPNs. Although rare, CML can also occur in childhood. The natural course of the disease occurs in three phases: chronic, accelerated and blast crisis. Most patients with CML are diagnosed in chronic phase [1]. As in CML, all other MPNs carry significant risk of terminating in acute leukemia. This transition may result from chromosomal instability in the original mutant stem cell or as the result of leukemogenic chemotherapy and radiotherapy for the original myeloproliferative neoplasm. Sometimes, it is very difficult to distinguish the different MPNs especially those in blast crisis and fibrosis. The treatment of CML involves targeted therapy namely, Imatinib mesylate, which is a tyrosine kinase inhibitor. Also, JAK1/2 inhibitors administered in PMF patients show clinical improvement [2]. So, it is Important to distinguish every MPNs even in their blastic phase as they have different treatment modalities in terms of targeted therapy depending on the underlying genetic abnormality.

\section{Case report}

A 32 year old lady presented with lower abdominal pain and distention for 6 months. She also had fatigue and palpitation for two months. On examination, she had pallor, generalized lymphadenopathy, hepatomegaly and massive splenomegaly. Her CBC values showed anemia $(8.3 \mathrm{gm} / \mathrm{dl})$ and leukocytosis $(19,500 / \mathrm{mm} 3)[3,4]$. Biochemical investigations showed raised LDH (2238 IU/L) indicating rapid cell turn over Figure 1.

Histogram (Figure 2) showed WL error which is due to the presence of normoblasts.T2 was absent that is indicative of a left shifted maturation [5].

RBC showed anisopoikilocytosis with microcytes, tear drop cells and pencil cells.53 nucleated RBCs/100 WBC. Corrected WBC count was 12,745/cu.mm. Differential Count- Polymorphs 26\% Stab 2\% Meta 3\% Myelocyte 6\% Promyelocyte $1 \%$ Eosinophil 3\% Lymphocytes 28\% Basophil 2\% Blast 25\%. 
Blasts were MPO negative. Platelet count was adequate. Large forms were seen (Figures 3,4).

A diagnosis of Acute leukemia associated with Primary myelofibrosis was considered from the peripheral smear. Tear drop cells are mostly seen in Primary myelofibrosis and are not usually associated with secondary myelofibrosis. We proceeded with bone marrow study.

Bone marrow aspirate yielded dry tap.

Marrow spaces were hypocellular with extensive fibrosis. Megakaryocytic hyperplasia was present with occasional dwarf megakaryocytes. Normal hematopoietic elements were suppressed (Figures 5-7).Dilated sinusoids were also seen (Figures 8).Condensation of the reticulin fibres will cause the sinusoids to pull apart resulting In their dilatation. Surprisingly, no immature cell clusters were seen in the marrow. Reticulin showed grade 3 fibrosis (Figures 9,10)

Flow cytometry (Figures 11 to 20) - Immature markers CD34 and HLA-DR, Myeloid markers - MPO, CD13 and CD33, Monocyte markers - CD36 were positive. Markers for B cell and T cell were negative. Philadelphia chromosome was detected by karyotyping and hence a final diagnosis of Chronic myeloid leukemia in fibrosis and blast crisis was made. Subtype - Acute myeloid leukemia.

\begin{tabular}{|c|c|}
\hline WBC- $19.5 \times 10^{3} / \mu \mathrm{L}$ & 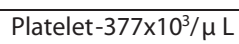 \\
\hline RBC-5.12X10 $/ \mu \mathrm{L}$ & LYM-37.9\% \\
\hline $\mathrm{Hb}-8.3 \mathrm{~g} / \mathrm{dL}$ & MXD------\% \\
\hline HCT-28.6\% & NEUT-----\% \\
\hline MCV-55.9fL & LYM-7.2X103/ $/ \mu \mathrm{L}$ \\
\hline $\mathrm{MCH}-16.2 \mathrm{pg}$ & 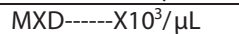 \\
\hline $\mathrm{MCHC}-29.0 \mathrm{~g} / \mathrm{dL}$ & 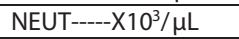 \\
\hline
\end{tabular}

Figure 1: Complete blood count.

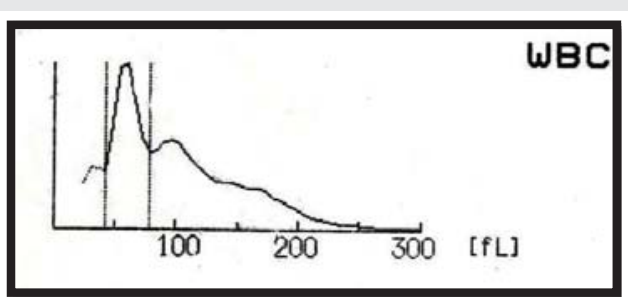

Figure 2: WBC histogram- showed WL error which is due to the presence of normoblasts. T2 was absent that is indicative of a left shifted maturation.

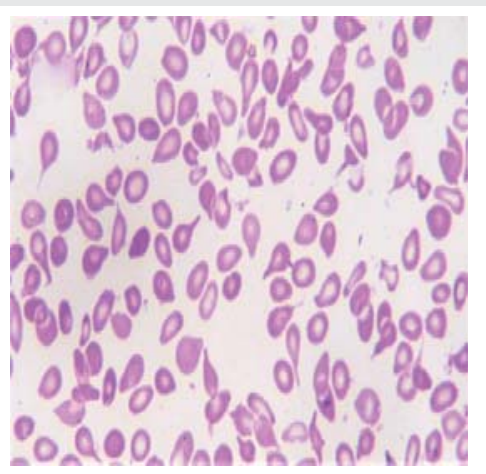

Figure 3: Peripheral smear- RBC shows anisopoikilocytosis with microcytes and tear drop cells.

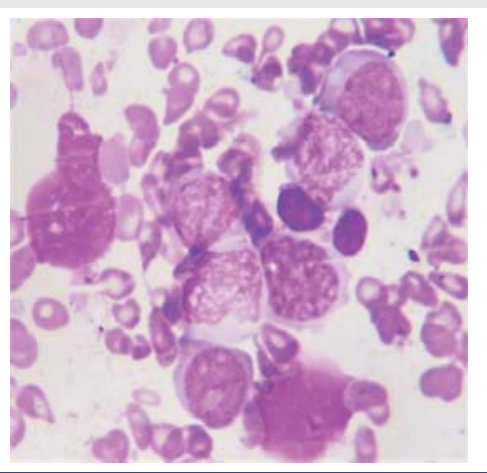

Figure 4: Peripheral smear- showing nucleated RBCs and blasts. Blasts are large cells with high $\mathrm{N}: \mathrm{C}$ ratio, open chromatin ,1-2 nucleoli and scant cytoplasm.

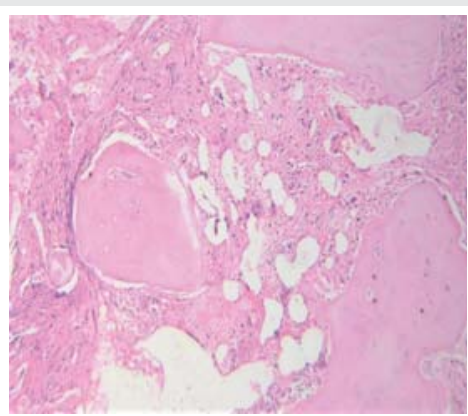

Figure 5: Marrow spaces were hypocellular with extensive fibrosis.

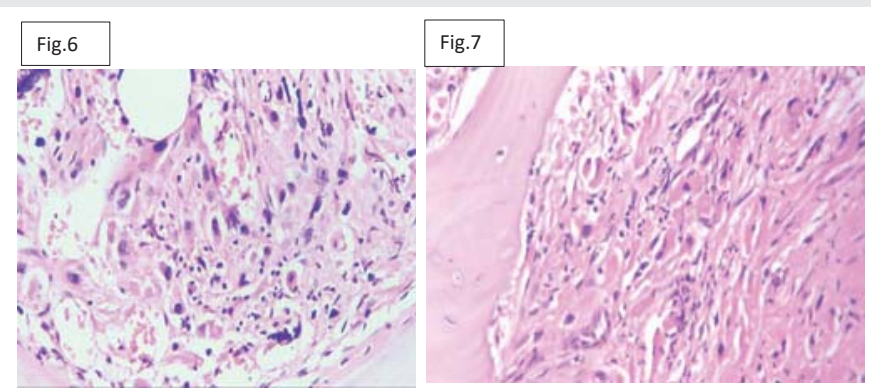

Figure 6,7: Megakaryocytic hyperplasia was present with occasional dwarf megakaryocytes. Normal hematopoietic elements were suppressed.

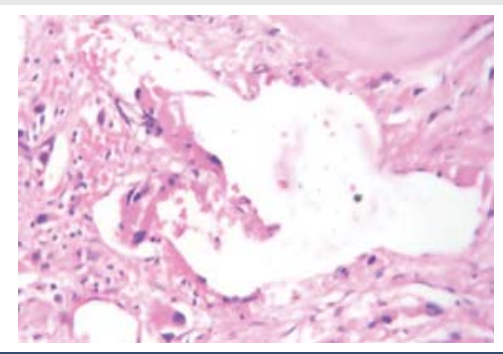

Figure 8: Dilated sinusoids.
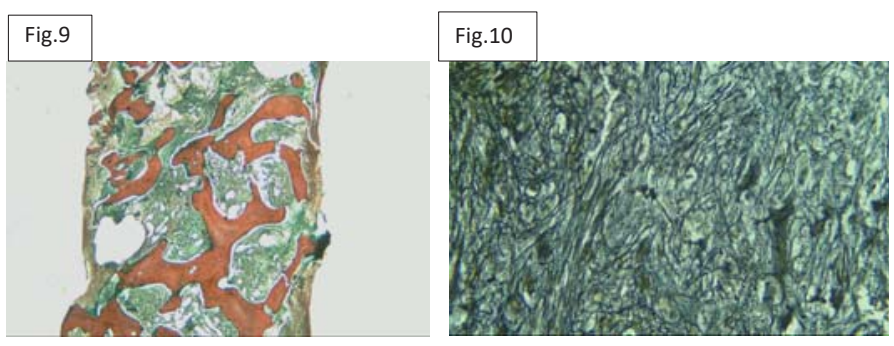

Figure 9,10: Reticulin showed grade 3 fibrosis.

Citation: Anju S, Jayalakshmy PL, Sundaram S (2021) Chronic myeloid leukemia mimicking primary myelofibrosis: A case report. Arch Hematol Case Rep Rev 6(1): 001-004. DOI: https://dx.doi.org/10.17352/ahcrr.000029 

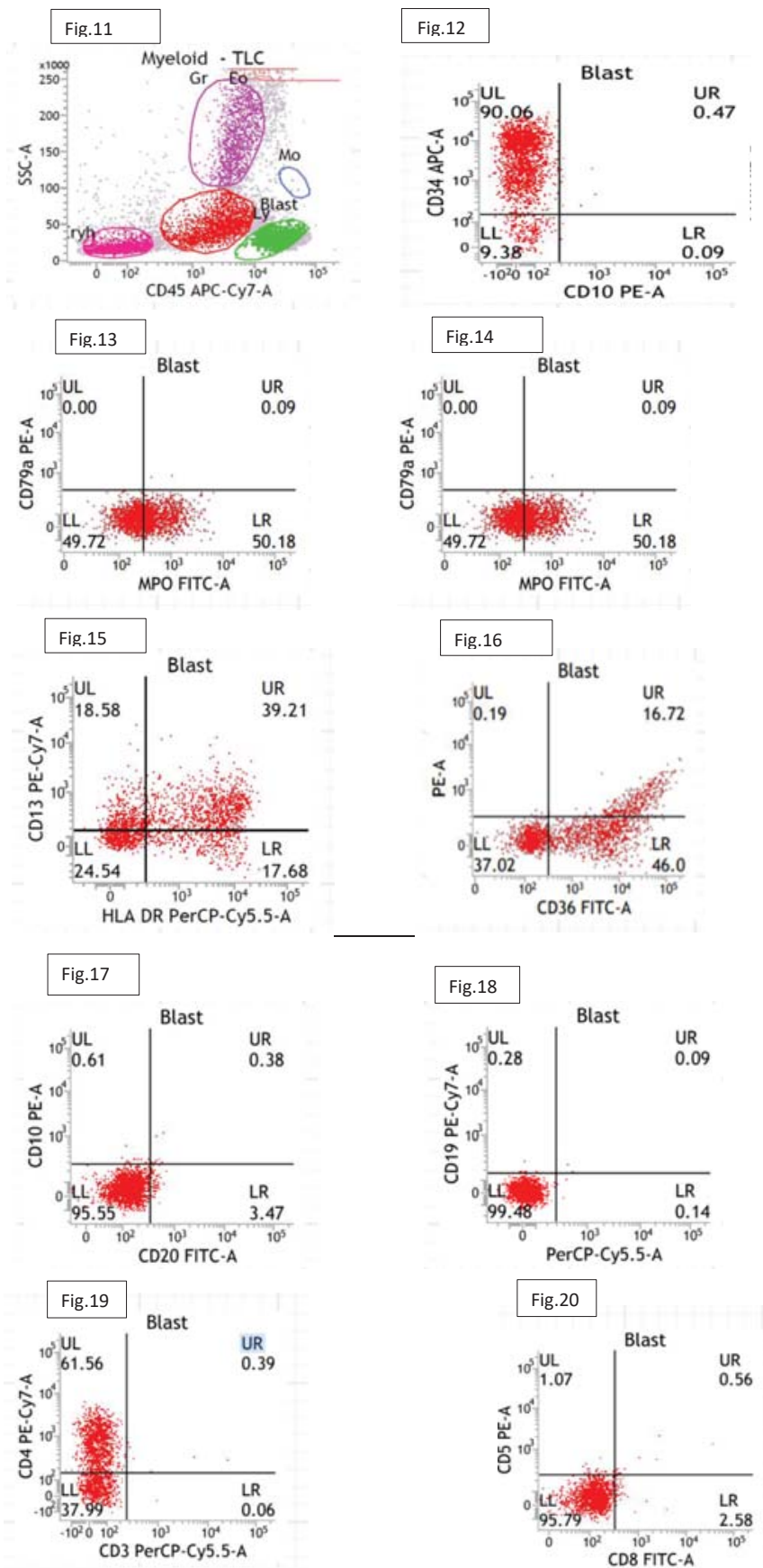

Figure 11-20: Flowcytometry- Immature markers - CD34 and HLA-DR, Myeloid markers - MPO, CD13 and CD33 and Monocyte markers - CD36 were positive. Markers for $\mathrm{B}$ cell and $\mathrm{T}$ cell were negative.

The patient expired 9 months after the diagnosis.

\section{Discussion}

Blast crisis remains the main therapeutic challenge in CML, even in the tyrosine kinase inhibitor era. Usually, blast crisis arises in patients with known CML, but it can be the initial presentation of the disease as in our case.

If untreated, typical CML progresses to the accelerated stage approximately 3-5 years after diagnosis. About 30\% of the patients die before developing blast crisis. Although blast crisis typically develops after a short accelerated phase, about one third of cases abruptly develop a blast transformation. After the onset of blast crisis, survival is about 1 to 2 months which is seen to be increased in patients receiving TKI therapy. About $65-75 \%$ of blast crises are myeloblastic and $25-35 \%$ are lymphoblastic. Blast crisis phase of CML is characterized by the presence of $\geq 20 \%$ blasts in the bone marrow or peripheral blood and or extramedullary blast proliferation and or presence of large clusters of blasts in the bone marrow biopsy. The hematologic criteria for identifying blast crisis is made by finding moderate to marked diffuse bone marrow fibrosis and $\geq 20 \%$ blasts in the peripheral blood or bone marrow of a patient previously diagnosed as having CML.

CML occasionally resembles Primary myelofibrosis. Splenomegaly, anemia and leucoerythroblastic blood picture are significant findings in both PMF and CML. In PMF, the leukocyte count is usually $<50,000 / \mathrm{cu} . \mathrm{mm}$, whereas in CML, the count is expected to be higher. In PMF, left shift of granulocytes is less pronounced and poikilocytosis is striking. The bone marrow in primary myelofibrosis is fibrous with large numbers of megakaryocytes. In CML also bone marrow can exhibit some fibrosis, but the most abnormal finding is myeloid hyperplasia. The LAP score is variable in case of myelofibrosis, but reduced levels is a strong evidence of CML. The most reliable test to distinguish CML from Primary Myelofibrosis is cytogenetic analysis for the Philadelphia chromosome.

In primary myelofibrosis, $10-15 \%$ patients progress to an acute myelogenous leukemia and some to acute lymphoblastic leukemia. JAK1/2 inhibitor when administered to Primary myelofibrosis patients is found to have clinical improvement.

In present case, younger age of presentation and initial presentation in blast crisis makes it a unique one. Although the presence of tear drop cells in the peripheral smear are favouring primary myelofibrosis, basophilia was a clue towards CML. Though hypocellular marrow with extensive fibrosis doesn't rule out primary myelofibrosis, 'dwarf megakaryocytic' morphology is a usual finding of CML. After all these dilemmas in findings, karyotyping revealed Philadelphia chromosome confirming the diagnosis of CML. In some cases of CML Philadelphia chromosome may be negative. Hence it is better to use RT-PCR to detect transcripts of BCR-ABL gene. Also, megakaryocytic morphology will provide essential clue to distinguish among the myeloproliferative neoplasms.

\section{Conclusion}

It is important to distinguish between myeloproliferative neoplasms, since they have distinct genetic aberrations, different lines of treatment, disease course and prognosis. We should consider a diagnosis of CML in blast phase, when peripheral smear shows blasts $>20 \%$ and bone marrow biopsy showing fibrosis even in younger age group.

\section{References}

1. Koshy J,Alperin J,Jana B, Markowitz A, Qian YW (2013) A case of Philadelphia chromosome positive myeloproliferative neoplasm in a pregnant woman with unsual primary myelofibrosis features. Case Rep Hematol 2013: 702831. Link: https://bit.ly/2Mm1Zkt 
2. Muehleck SD, McKenna RW, Arthur DC, Parkin JL, Brunning RD (1984) Transformation of chronic myelogenous leukemia: clinical, morphologic and cytogenetic features. Am J Clin Pathol 82: 1-14. Link: https://bit.ly/3cudml9

3. Laibe S, Tadrist Z, Arnulet C, Sainty D, Mozziconacci MJ (2009) A myeloproliferative disorder may hide another one. Leuk Res 33: 1133-1136. Link: https://bit.ly/3jcUmZB
4. Jabbour E, Kantarjian H (2012) Chronic myeloid leukemia: 2012 update on diagnosis,monitoring and management. Am J Hematol 87: 1037-1045. Link: https://bit.ly/3asTRqy

5. Thiele J, Kvasnicka HM (2006) Myelofibrosis in chronic myeloproliferative disorders-dynamics and clinical impact. Histol Histopatho 21: 1367-1378. Link: https://bit.ly/39BysfB

\section{Discover a bigger Impact and Visibility of your article publication with}

\section{Peertechz Publications}

\section{Highlights}

* Signatory publisher of ORCID

- Signatory Publisher of DORA (San Francisco Declaration on Research Assessment)

* Articles archived in worlds' renowned service providers such as Portico, CNKI, AGRIS, TDNet, Base (Bielefeld University Library), CrossRef, Scilit, J-Gate etc.

* Journals indexed in ICMJE, SHERPA/ROMEO, Google Scholar etc.

- OAI-PMH (Open Archives Initiative Protocol for Metadata Harvesting)

* Dedicated Editorial Board for every journa

* Accurate and rapid peer-review process

* Increased citations of published articles through promotions

* Reduced timeline for article publication

Submit your articles and experience a new surge in publication services (https://www.peertechz.com/submission).

Peertechz journals wishes everlasting success in your every endeavours.

Copyright: @ 2021 Anju S, et al. This is an open-access article distributed under the terms of the Creative Commons Attribution License, which permits unrestricted use distribution, and reproduction in any medium, provided the original author and source are credited. 